after adolescence and is often caused by excessive alcoholic indugence. A priori, one would expect to find that the symptoms of premature senility induced by alcoholic intemperance would be similar to those which are met with in cases of physiological senility, and, to a certain extent, this is so ; that is to say, the symptoms which are dependent upon the alteration in the brain tissue, due to the atberomatous condition of the bloodressels, are the same. But in the case of premature senility induced by alcohol there are, in addition to such symptoms, others which are dependent upon the direct action of alcohol on the nerve tissues. Atheroma of the bloodvessels of the brain may result (1) in atrophy of the brain, and (2) in softening of the brain. Atrophy of the brain is due to insufficient supply of blood, consequent upon the diminished lumen of the vessel, and upon the destruction of the elasticity of its coats. Softening of the brain is due to the blood supply being entirely cat off, by the formation of a thrombus in the vessel. The symptoms of the latter are practically an exaggeration of those of the former and partake of the nature of a general mental enfeeblement, varying in degree between partial and complete dementia. These symptoms are, as a rule, gradual in onset, and in some cases are the only ones to be met with. In other cases, in addition to these symptoms, there are those of mania or melancholia, consequent upon the action of alcohol on the nerve tissues themselves. The latter symptoms are usually sudden in onset and of ten recur again and again.

3. Alcoholic abuse acting in conjunction with moral or physical causes. - Strictly speaking, perhaps it is incorrect to speak of these two causes acting in conjunction with one another, but rather in relation of cause to effect. They, however, act and react on one another to so great an extent--the one sometimes being the cause, sometimes the effect, of the other-that the effects of both are combined in the causation of the ultimate result. For example, it must have been everyone's experience to have met with cases in which the mental depression caused by business anxieties, pecuniary difficulties, loss of relatives and friends or mental worry of other kinds has led to the habit of the excessive use of stimulants for the purpose of relieving temporarily such mental depression. Such relief, however, is but temporary; and when its effects have passed off the mind is more depressed than before, the result being that relief is again sought in alcoholic stimulation and the habit becomes confirmed. On the other hand, there are cases in which intemperate habits lead to ruin in business, alienation from friends and relatives, loss of self - respect and the mental disquietude consequent upon these. From a clinical point of view there is a difference in the type of insanity in these two classes of cases. In those cases in which the mental depression has led to a habit of intemperance, the symptoms are as a rule those of delusional mania and the delusions often lead to acts of violence. In those cases in which the mental depression has followed upon alcoholic excess and its results the symptoms are as a rule those of melancholia. In such cases acts of suicide and homicide are common and are altruistic in character.

4. Alcoholic abuse acting in association with certain physical causes: (1) sunstroke, and (2) injury to the head.--Although in many cases the recovery from sunstroke is so complete that no after effects are noticeable, yet in the majority of severe cases more or less distinct nervous symptoms, such as impairment of memory, nervous irritability, partial paralyses, epilepsy \&c., remain permanent for the remainder of the patient's life. The pathology of sunstroke is at present not very definite, but, whatever it may be, there can be no doubt that it leaves a predisposition to insanity, and indeed in some cases it must be considered to be the sole cause of the mental disorder. One of the most common and noticeable changes in persons who have suffered from sunstroke is their extreme snsceptibility to the effects of alcohol, and as a result of this a comparatively slight over-indulgence in it is often the exciting cause of insanity in them. Clinically, cases of this kind resemble in every respect cases of acute a]coholism. The effect of injuries to the hearl in their relation to alcoholic intemperance and insanity is practically the same as that of sunstroke; that is to say, there is often after injury to the ke id an extreme susceptibility to the effects of alcohol, so that a comparatively small quantity will cause an attack of acute maniacal excitement in every way similar to an attack of acute alcoholism. In many case also there is a great change in the manner in which the ernotions are affected in the early stages of intoxication; for example, one who formerly became hilarious and jolly under the effects of alcohol will, after having received an injury to the bead, become quarrelsome and pugnacions under its effects.

The following statistics bear upon the whole subject under consideration. During the ten years ending Dec. 31st, 1892 . there were admitted into Broadmoor Asylum 325 criminal lunatics. In the case of 86 , or 26.46 per cent, of these alcoholic intemperance was assigned as a cause of their insanity. Of these 86,30 , or 34.88 per cent., had hereditary history of insanity, and 13 , or $15 \cdot 11$ per cent., had hereditary history of intemperance. With regard to other causes in association with intemperance, domestic trouble, adverse circumstances, mental worry \&c. were assigned as a cause in 14 cases, or 16.27 per cent. Sunstroke was assigned as a cause in 10 cases, or 1162 per cent. Injury to the head was assigned as a cause in 9 cases, or 10.46 per cent. Previous attack was assigned as a cause in 20 cases, or 23.25 per cent.; of these, alcoholic intemperance was known to be the cause in 15 out of the 20 cases.

\section{EXCISION OF SPINA BIFIDA.}

BY A. W. MAYO ROBSON, F.R.C.S. ENG.,

HON. SURGFON, LEEDS GENERAL INFIRMARY; PROFESSOR OF SURGERT IN TIIE YICTORIA UNIVERSITY.

Is 1885 I reported at a meeting of the Landon Clinical Society a series of cases of spina bifida treated by excision of the sac, which treatment I advocated as being applicable to the greater number of cases calling for active interference. At the same time I showed patients who had been treated by this method. Attention was drawn to the following points: 1. The principle of closing the meninges by bringing together two serous surfaces, as in peritoneal surgery, and superimposing separate skin flaps, the meningeal and skin lines of suture not being opposite. 2. The great importance of observing strict antiseptic precautions, as a septic condition would probably end in the same way as these cases usually do when they spontaneously ulcerate-viz., by meningitis and convulsions. 3. The success attending the plastic operation in cases which are absolutely not amenable to any other form of treatment-e.g., when the coverings are thin or the opening into the spinal canal is large. At the same time I proposed the following classification: (1) Where an operatior: should not be done; (2) where an operation is not called for; and (3) where an operation should be performed.

Class 1. - Where an operation shonld not be aone 1. Where the deformity is very extensive, as in fissure of the whole or a considerable portion of the vertebral caral. 2. Where there is complete paraplegia. 3. Where the sac is large. the fissure extensive and the coverings are excessively thin quite to the edge of the tumour and no skin can be obtained to cover the meninges. But that such extrerse cases may stand a chance of cure is proved by several cases successfully treated.

Class 2 -Nothing need be done where the sac is small and the coverings are so dense and firm as to form a good pad over the opening in the spinal columr.

Class 3.-Where some operation should be done : 1. Where the sac only communicates with the spinal canal by means of a small opening. Here it is a simple matter to dissect of the skin, expose the neck of the sac, ligature it by means of one circular ligature and cut off the red undant meninges, bringing the skin over so as to have the line of skin sutures quite at the side away from the pedicle. 2. Where the sac has a good skin cover and communicates with the spinal canal by a large opening it is quite easy to carefully excise it and close the meninges, placing if pos. sible the line of skin sutures away from the meningeal line of union. 3. Where the coverings are excessively thin quite to the edge of the tumour the operation is more difficult and uncertain, as the skin can only be obtained by a process of sliding from the contiguous parts and the tension necessarily present is not conducive to healing. 4. Where the spinal cord or the nerves are blended with the sac-a condition which cannot often be diagnosed until the dissection of the skin from the meninges is made-I have excise? portions of the redundant meninges from between the nerves, replacing the nerwous structures in the spinal canal and covering by a flap of skin; or, if this cannot be dore, the membranes may be punctured, the collapsed sac with the nervous structures intact be placed in the canal, and the skin 
cover made as before. It is important to remember that a silver, or leather shield, should be worn over the site of operation in order to protect the parts from injury and to prevent the cicatrix from stretching or giving way.

The following extraordinary case, which was sent to me by Dr. McGregor of Huddersfield and reported by my late house surgeon, Mr. Basil Hall, affords a good illustration of the treatment of spina bifida by excision. Figs. 1. and

\section{FIG. 1.}

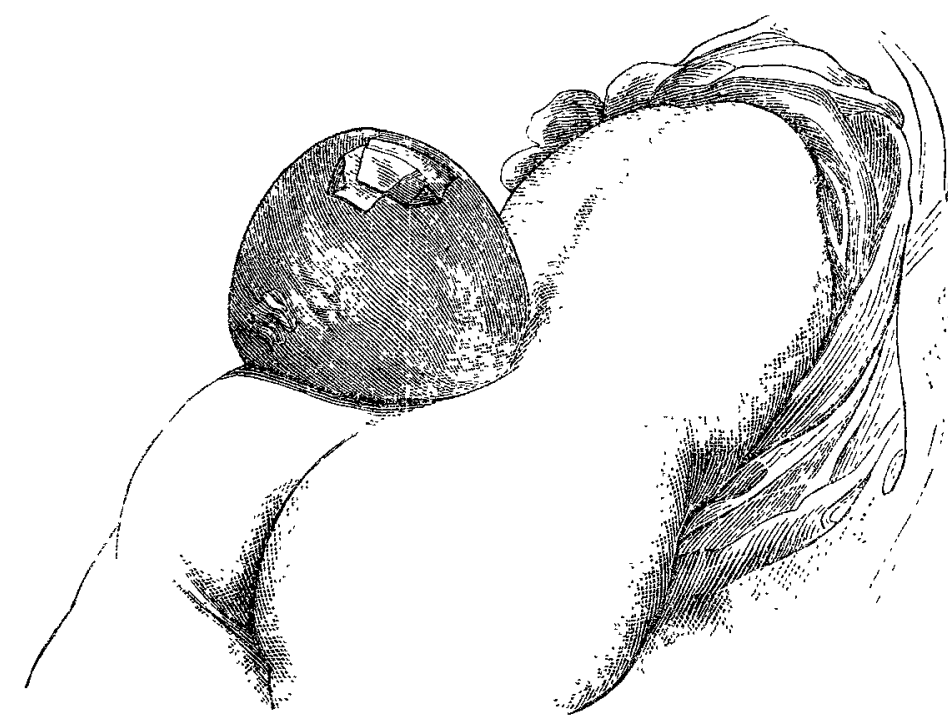

2 give a good idea of the enormous size of the tumour and Wig 3 shows the appearance some weeks after operation. A. man thirty-five years of age, residing at Mold Green,

FIG. 2.

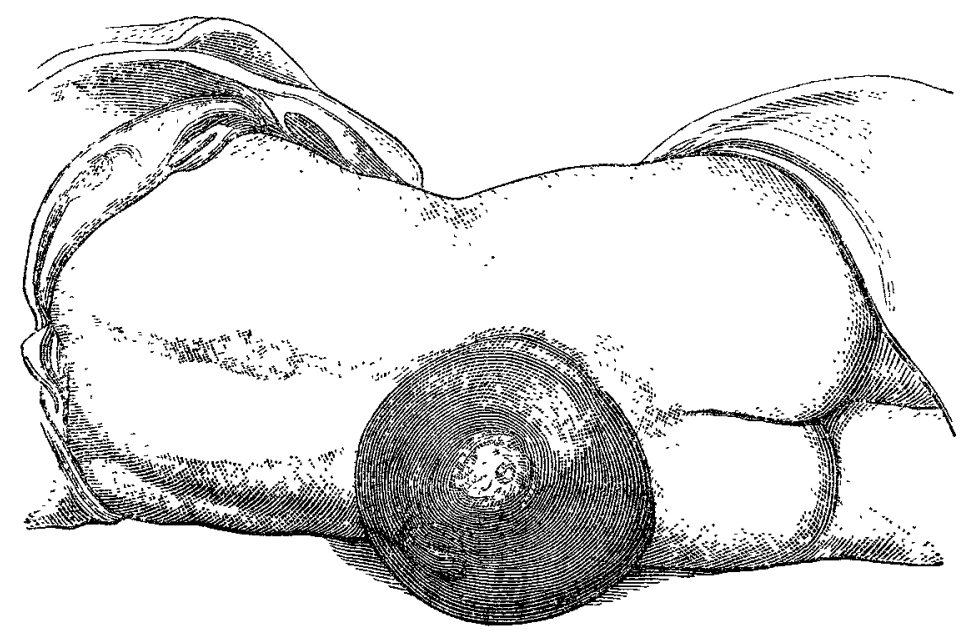

was admitted to the Leeds General Infirmary on Feb. 26th, 1891, on account of an enormous spina bifida. which caused him to walk in a stooping posture and compelled him to

FIG. 3.

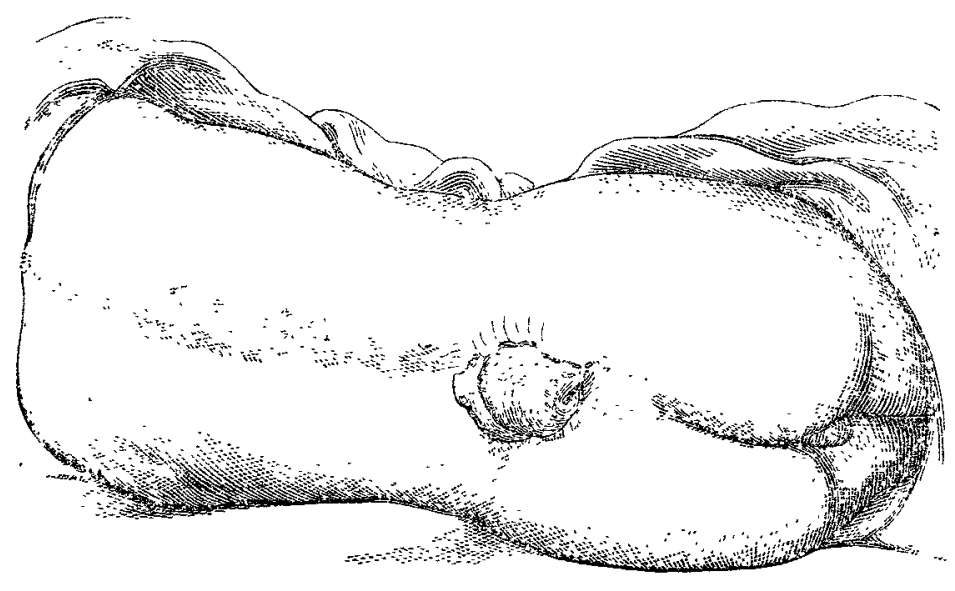

avoiủ crowded assemblies lest he should be injured. He stated that he had had the tumour all his life, but he had been told that it was at first only of the size of a walnut. r'here had never been any paralysis or discomfort of any kind caused by it, except a little tenderness when firmly pressed on. In November, 1890, the sac was accidentally ruptured and a thin watery fluid escaped; again, in December of the same year, and also in January, five weeks before admission. a similar accident happened, necessitating each time prolonged rest. The tumour had considerably increased in size of late. On admission it measured eighteen inches in circumference and was covered with thick skin near the circumference. but only by thin parchment-like membrave at the fundus. (See illustration). It was evidently filled with thin fluid and no trace of cord or nervous structures could be felt in the sac. Ether having been administered, an incision was made through the skin over the tumour and a flap was marked out of the integuments sufficient to cover the stump. the base of the flap being below. After this had been clissected of the membranes the sac was punctured and four pints of watery fluid (clearly cerebro-spinal) were removed. The sac was then dissected up from the surrounding tissue and the neck exposed and ligatured with chromicised catgut; the sac beyond the ligature was removed and the skin flap was adjusted over the stump and closed by interrupted sutures, no drainagetube being employed. The wound healed by first intention except for a small point at the lower angle, and this closed by granulation. When the man was seen on April 3rd as an out-patient the wound was quite sound and there was no sign of hulging. He had walked several miles to report himself.

The case is of interest not only on account of the success of the treatment adopted but from the age of the patient, the enormous size of the tumour and the fact that the lattcr had been accidentally ruptured without inducing meningitis. From the considerable number of cases I have seen, many of which have been operated on, I cannot help thinking that meningocele is by far the most frequent form of spina bifida, and a continued experience leads me to state that the disease in nearly all cases that call for interference may be treated by excision of the sac, or some modification of this, with a great probability of success.

Hillary-place, Leeds.

\section{THE DIAGNOSIS BETWEEN RÖTHELN AND SCARLET FEVER:}

A LESSON AND A PROBLEM IN PREVENTIVE MEDICINE. BY F. P. ATKINSON, M.D. ABERD. \&C.

THE correct diagnosis between rötheln and scarlet ferer is often a matter of very great importance and it is also one of extreme difficulty. When one refers to the various authorities on the subject the most conflicting opinions are to be met with. One says that the rash is like scarlet fever, another that it is like measles; one that it comes out with the fever, another that it appears two or three days after its commencement; one that it is ushered in with coryza, another that there is no coryza; and one that there is little or no desquamation. another that there is extensive peeling even of the hands and feet. With such diversity of opinion, how can the medical practitioner be expected to arrive at a correct diagnosis of these cases? One thing, I think, is certain, and that is that one must not rely either on the appearance of the rash or on desquamation; but there are two symptoms. nevertheless. which are well marked in nearly every case-viz.. the initial fever is very short and the glandulæ concatenate are distinctly enlarged. It is more easy, of course, to detect the real nature of an epidemic when it occurs amongst a number of persons who are associated together in one dwelling than when they are scattered about in various localities, though at first, perhaps, even here the diagnosis may be somewhat doubtful. On June 7th of the present year I was called to see a boy aged twelre years at school, who had a somewhat dark, scarlatinal-looking rash on the neck and chest, a slightly ulcerated throat and enlargement of the glandulæe concatenatæ. The temperature was a little over $100^{\circ} \mathrm{F}$. On the third day he was perfectly mell in erery respect. consequently the case appeared to me to be one of rôtheln. By way of precaution, he was ordered to be kept in quarantine for two weeks, to have an antiseptic bath at the end of that time, and to be dressed in perfectly fresh clothes before being allowed to mix with the other boys. Unfortunately, one important direction was omitted-riz., 